\title{
La poética de la espiritualidad y lo introspectivo en la obra de Younes Rahmoun. Hacia una lectura del arte distanciada de los cánones historicistas.
}




\section{THE POETICS OF SPIRITUALITY AND THE INTROSPECTIVE IN THE WORK OF YOUNES RAHMOUN. HE MADE A READING OF ART DISTANCED FROM THE HISTORICIST CANONS.}

\section{ABSTRACT}

The present study is formulated in a situation saturated with fixed and essentialist images of the Arab and Muslim individual, which tries to typify the difference in absolutes, without taking into account the existing diversity. In this sense, we propose to go beyond the usual historicist canon to be able to develop a specific analysis of the work of an non-western artist, who contradicts modern reason to reflect through art on the spiritual experience in the Muslim faith. It is, therefore, an approach to the work of the Moroccan artist Younes Rahmoun, built from an interdisciplinary perspective, in which we analyze the relationships between his artistic discourse, his spiritual convictions and his life experience. For this, by way of contextualization, we define the underlying reasons behind the aesthetic-conceptual and narrative choices used by Rahmoun. Indeed, we start from the conviction that we are not facing an artistic experience isolated from its cultural, social, political, economic, historical and cultural reality; but a continuity integrated in the context, which works in harmony with existing styles, reflections and ways of life in the local and global environment.

\section{Keywords}

Art, otherness, spirituality, self-representation, poetics.

\section{RESUMEN}

El presente estudio se formula en una situación saturada de imágenes fijas y esencialistas sobre el individuo árabe y musulmán, que intenta tipificar la diferencia en absolutos, sin tener en consideración las diversidades existentes. En este sentido, planteamos como principio a seguir, ir más allá del canon historicista habitual para poder desarrollar un análisis específico sobre el trabajo de un artista extra-occidental, que contradice la razón moderna para reflexionar, a partir del arte, sobre la experiencia espiritual en la fe musulmana. A partir de una aproximación a la obra del artista marroquí Younes Rahmoun, construida desde una perspectiva interdisciplinar, analizamos las relaciones existentes entre su discurso artístico, sus convicciones espirituales y su experiencia vital. A modo de contextualización, definimos las razones subyacentes tras las elecciones estético-conceptuales y narrativas empleadas por Rahmoun. En efecto, partimos del convencimiento de que no estamos ante una experiencia artística aislada de su realidad cultural, social, política, económica, histórica y cultural; sino ante una continuidad integrada en el contexto, que funciona en armonía con estilos, reflexiones y modos de vida existentes en el entorno local y global.

\section{Palabras clave}

Arte, otredad, espiritualidad, auto-representación, poética. 


\section{INTRODUCCIÓN}

En De lo espiritual en el arte Vassily Kandinsky nos sugiere pensar en la relación existente entre la espiritualidad y la reflexión introspectiva para que el espectador sea capaz de emocionarse con ella. Para él, las formas del arte deben convertirse en alimento espiritual, donde "el estado de ánimo de la obra puede profundizar y modificar el estado de ánimo del espectador" (Kandinsky, 1989, p.10). Se trata por tanto de comprender la espiritualidad a partir de la realidad del artista, su contexto vital y sus convicciones. Precisamente en este último punto se sitúa la obra de Younes Rahmoun, donde el artista marroquí se encuentra en la parte más alta del "triángulo de la contemplación gozosa" que delinea Kandinsky para jerarquizar los modos con los cuales se transmite el mensaje. (1989, pp.37-39) No obstante, esto no quiere decir que estemos ante el trabajo de un artista que representa el ideal romántico del arte que separa al artista de su contexto. Por el contrario, el trabajo de Rahmoun profundiza en la lectura espiritual de su entorno, aplicando la mirada kantiana de lo sublime, de aquello que sobrepasa nuestra capacidad de razonamiento y progresa hacia el infinito, donde la magnitud de las cosas no llega a ningún máximo, haciéndonos ver que somos minúsculas materias dentro del universo (Kant, 2003). En otras palabras, el trabajo del artista objeto de estudio asume la subjetividad del valor del significado de las cosas del mundo que lo rodea, no sólo como estado mental, sino también como unidad estética que refleja la complejidad de lo divino. La obra de arte por tanto es inseparable de la experiencia vital, es "un estado de anticipación de la conciencia que es la intención de reflexionar" (Read, 1975, p.163), donde más allá de abogar y/o defender convicciones espirituales determinadas, se propone un distanciamiento de la descripción lineal. Rahmoun a partir de su proceso meditativo-artístico busca la esencia de su alma como parte inseparable del espíritu. Para ello, su estrategia narrativa no es dogmática ni pretende ofrecer ninguna apología a un ideal religioso o político, su principio reside en la seducción poética que concibe al espectador como sujeto activo-participativo. Se trata, de mantener el fuego de la pasión espiritual, pero sin introducirse en él, es decir, disfrutar de la luz divina y hacer que el público sea capaz de reproducir su esencia. 


\section{MÉTODO}

En este estudio adoptamos como metodología de trabajo la perspectiva derridiana, en cuanto a la filosofía de la historia (Nava Murcia, [2012, pp.95-126). El propósito es repensar la manera con la que se analiza y se representa la creación artística procedente del Mundo Árabe, que como formula el artista libanés Walid Raad en su proyecto Scratching on Things I could Disavow (2007), no necesariamente se tiene que articular mediante narrativas estructuradas en espaciotiempos separados, como sucede en la historia del arte moderno (Panzani, 2012, pp.166167). La idea de Raad se anuncia como respuesta a la especulación sin precedente del arte contemporáneo que existe en la actualidad, especialmente en algunos países del Golfo Pérsico. El fin de estos esfuerzos según él, no reside en la promoción del arte árabe, sino en su valor económico. Para ello, se requiere la adopción de códigos artísticos reconocibles por el capital, sobre todo en un contexto en el que no se ha desarrollado una tradición de la crítica artística. El Mundo Árabe, según la profesora de Historia del Arte en la Universidad del Norte de Texas, Nada Shabout nunca ha tenido una teorización estética, teniendo en cuenta que históricamente el concepto de arte tal y como lo ha definido la Modernidad, se introduce en el Mundo Árabe a través de los artistas orientalistas y más tarde por medio de las escuelas y los centros culturales vinculados a los países europeos colonizadores. No es hasta mediados del siglo XX, cuando empezamos a hablar de movimientos artísticos árabes. De ahí podemos comprender el porqué de la no existencia de una profesionalización de la crítica artística árabe. En el Mundo Árabe como explica Shabout nunca han existido figuras como "Baudelaire y Clement Greenberg" (2009, p.18).

En medio de este vacío teórico, según Shabout, después de los atentados del 11 de septiembre y paradójicamente en un momento de incertidumbre y miedo hacia lo árabe y lo islámico, comienza a verse una mayor inclusión artística (2009, p.14). La investigadora Safia Belmenouar en un artículo publicado en Transcontinentales (2012, p.13), contextualiza concretamente este proceso de inclusión, en el que los artistas árabes, que a menudo estaban excluidos, de repente se convierten en un foco de interés. Esta idea es la que detalla la profesora de Historia del Arte Moderno de la Universidad del Estado de California, Staci Gem Scheiwille (2018, pp.195-230), afirmando que la inclusión en el caso específico de los artistas árabes formaba parte de las estrategias propagandísticas de la administración de Bush para legitimar la guerra en Afganistán e Irak. La estrategia mediática en este momento de tensión y miedo, en opinión Scheiwille consistía en crear dos imágenes contradictorias. Por un lado, la del individuo árabe que cita Edward Said en su ensayo Orientalismo (2013), que cambia su indumentaria de turbante y espada curva por la Kalashnikov ${ }^{1}$ en la mano y por otro, la imagen del árabe intelectual próximo a los ideales occidentales, donde es abarcada la figura del artista árabe contemporáneo, que se presenta como víctima de una "cultura injusta". De tal manera, para que la inclusión del Otro árabe se haga efectiva, es necesario desarrollar argumentos teóricos que sean identificables, es decir, recorrer al canon historicista. En este contexto, en palabras de Shabout, aparecen críticas artísticas que no tienen en consideración las características específicas de la creación árabe (2009, p.14). Estos intentos de teorización, se fundamentan esencialmente en imponer una normalización homogeneizadora, sin atender las especificidades existentes de cada artista. De todo ello se desprende en este estudio, nuestro propósito de generar lo contrario a la visión hegemónica, no siguiendo así con la retórica habitual, para poder desarrollar una aproximación específica a la obra de Rahmoun, uno de los artistas marroquíes con mayor proyección internacional. La lectura que realizamos de la trayectoria de Rahmoun no se reduce 
solo a aspectos determinados, como lo autorreferencial o la espiritualidad, sino que también se formula a partir de los márgenes del pensamiento que defiende Jacques Derrida en Márgenes de la filosofía (2006), donde no hay puntos de vista únicos, sino que la comprensión es resultado de la complejidad del pensamiento.

\section{DESARROLLO}

\subsection{Representación histórica unilateral}

A partir de la idea de la complejidad del pensamiento, encontramos sincronías entre la crítica colonial de Franz Fanon en Los condenados de la tierra (2017) y la obra de Rahmoun, especialmente en la conciencia estética comunitaria local y el establecimiento de prototipos formales simbólicos que mantienen relación con las necesidades vitales. El arte y la espiritualidad para Rahmoun forman parte de una unidad, un punto de vista contrario a las divisiones habituales entre las formas del arte aplicado y el arte comprendido como originalidad mágica. Las expresiones artísticas cotidianas locales que introduce Rahmoun en su producción artística, desde la perspectiva de Fanon, fueron "condenadas en nombre de un estilo artístico codificado, de una vida cultural desarrollada dentro de la situación colonial" (2017, p.189). Fanon aquí propone una necesaria conciencia que emerge desde el sur, de comprenderse a uno mismo y concebir el mundo de manera distinta, porque según él, poner en valor lo local hace "nacer la esperanza e impone un retroceso al universo racista" (p.189). El cambio en las formas del arte que aquí se reivindica, radica en el diagnóstico de la historia desde la perspectiva de los impactos psicológicos de la opresión (Said, 2019, pp.82-86). El argumento de Fanon se asemeja al de Walter Benjamin en Tesis de la filosofía de la historia (2008), que afirma que la historia ha sido contada desde una narrativa unilateral, donde existe una relación de subalternidad basada en el poder del observador sobre el observado. En otras palabras, la mirada del observador estudioso occidental, desde el punto de vista de Fanon, es similar a la mirada de un turista que construye sus relatos y opiniones sobre los lugares que encuentra en su camino desde el interior de su vehículo. Aquí cabe destacar la investigación de Mery Sut Favaretto, Las Fronteras de los archivos. Lo exótico en Pasolini (2019, pp.52-73), en la que pone en contexto el trabajo antropológico de Pasolini. Sut Favaretto, establece una reflexión crítica sobre la mirada despegada de Pasolini como individuo europeo rico, que percibe lo que ve como un escenario teatral. De esta manera, según ella, se considera todo lo que se escapa del entendimiento racional como caos y escaso de sentido. En efecto, se podría decir que la historia funciona como un sistema de absorción impulsado por la obsesión de narrar y opinar por medio del archivo. Pero dicha absorción tiene siempre un filtro, donde todo lo filtrado es considerado como parte de la historia universal.

La importancia de este estudio por tanto, reside precisamente en no contentarse con lo normativo y estructural, en analizar con detenimiento aquello que ha quedado fuera y en los márgenes. Lo que queremos decir con ello, es que estamos ante el trabajo de un artista que quizás no entra en las categorizaciones habituales, ya sea por el simple hecho de proceder del sur global o por su discurso artístico que contradice y pone en tela de juicio la imagen estereotipada sobre el islam. La obra de Rahmoun estéticamente y conceptualmente se situaría en el espacio de consignación del archivo que se constituye según el artista franco argelino Kader Attia en su proyecto The Repair from Occident to Extra-Occidental Cultures (2012) por dos partes: la primera es visible -con un aparente orden- que sería el espacio museo, mientras 
la segunda es el espacio "almacén", lugar oscuro, frío, húmedo y polvoriento. Precisamente en "el espacio almacén" es donde podemos situar las tradiciones culturales de los pueblos extra-occidentales (Attia citado por Malraux, A, 2013). Un hecho que se encuentra alineado con los acontecimientos históricos que delinea Said en Reflexiones sobre el exilio (2013), donde afirma que hasta finales de la Segunda Guerra Mundial solo había dos géneros de habitantes del mundo: colonizadores y colonizados. Todo lo que no era occidental estaba bajo la dominación y por lo tanto era colonizado y subalterno. La inclusión de la otredad como señala Said:

\begin{abstract}
"Solo ocurrió cuando personajes subalternos como las mujeres, los negros y demás "indígenas" hicieron el suficiente ruido para que se les prestara atención y, por así decirlo, se les preguntara. Antes de eso se ignoraba más o menos que estuvieran allí, como a los criados de las novelas del siglo XIX, y solo se reparaba en ellos nada más que como una parte útil del escenario" (p.275).
\end{abstract}

\title{
3.2 Influencias históricas, contexto y formas particulares de entender el arte
}

Haciendo un paralelismo entre el trabajo de Rahmoun y la contextualización histórica que hemos desarrollado en el anterior apartado, nos damos cuenta enseguida que estamos ante un debate no resuelto y una continuidad de aquellas fórmulas artísticas de legitimación postcoloniales de los años 50 y 60 . Nos referimos con el debate no resuelto, a los movimientos artísticos árabes hadatillin (modernos) que pretendían volver a la esencia de las tradiciones locales, asumiendo las utopías formuladas por Fanon que establecen una posible emancipación de los pueblos colonizados, a través de la puesta en valor de sus patrimonios locales. Fanon, considera que el logro del poder colonial no solo se manifiesta en el peso de la dominación, sino también en su capacidad de actuar en el intelecto, de hacer que los intelectuales del sur desprestigien sus culturas y abracen ciegamente "la cultura del ocupante, cuidándose de caracterizar peyorativamente su cultura nacional” (2017, p.185). El abrazo, según Fanon, en ningún momento significa una aceptación del Otro, más bien su anulación. Frente a esta realidad, la utopía de Fanon armoniza con la idea de la conceptualización del poder que formula Michel Foucault (1988, pp.3-20), que implica en opinión de Fanon desarrollar un pensamiento crítico que lleva a la conciencia histórica de nuestras circunstancias actuales. En el campo de la producción cultural del sur global, dicha conceptualización requiere recuperar e introducir las formas del arte popular como la narración oral o las artes aplicadas (2017, pp.161-193). Esto nos ayuda a entender la constante búsqueda de elementos simbólicos que emanan de la realidad cultural local, que caracteriza el proceso creativo del artista objeto de estudio. Rahmoun, al buscar la parte espiritual a la que en ocasiones define como "alma", reclama la necesidad de prestar atención a otra lectura de lo estético. Lejos de los límites impuestos por la academia, que fueron importados a través de las escuelas de bellas artes en Marruecos, Rahmoun recupera el pulso de los artistas marroquíes de la Escuela de Casablanca: Farid Belkahia, Ahmed Cherkaoui, Mohamed Melehi y Mohamed Chabaa. Estos, reclamaban indagar en el Aturat al magrebí (patrimonio marroquí) para recuperar su esencia original, antes de convertirse en "fetiche turístico" automatizado. Diciéndolo de otra manera, tratar de revalorizar la cultura autóctona lejos del marco normativo, heredado del pasado colonial. (Barroso Villar, 2014, p.87).

Volver a estos pilares, casi históricos del arte marroquí, resulta siempre necesario para poner en contexto el trabajo de Rahmoun. De hecho, como indicamos en la metodología de este estudio, concebimos el pensamiento desde la complejidad, es decir entendemos la obra de 
Rahmoun desde una visión distanciada y a partir de las conexiones existentes, tanto con su contexto local como su contexto global. Cuando Rahmoun adopta el argumento discursivo de los artistas de su entorno, de una manera u otra lleva a la práctica las tesis de Fanon y Foucault. Estos consideraban el poder que gestiona a su antojo la historia, no solo como una cuestión teórica, sino también como experiencia emocional que actúa y condiciona los comportamientos humanos. En otras palabras, Rahmoun de este modo contradice la racionalidad moderna que defiende la tesis de Adolf Loos en la conferencia Ornamento y delito (1908), en la que sostenía que:

(...) "el ornamento ya no pertenece orgánicamente a nuestra civilización, tampoco es ya expresión de ella. El ornamento que se crea hoy ya no tiene ninguna relación con nosotros ni con nada humano; es decir, no tiene relación alguna con la actual ordenación del mundo" (Loos, 1908, p.4).

Esta visión de la modernidad, como sinónimo de ruptura con el ornamento, que reivindicaba Loos en opinión de Mounir Fatmi (2011), ha sido clave en la percepción del arte árabe en Occidente. Desde el punto de vista de Fatmi, hasta hace prácticamente poco, la creación artística árabe ha sido siempre asociada a las artes aplicadas, a menudo juzgadas por los críticos del arte contemporáneo como primitiva, artesanal o demasiado superficial. Por tanto, poner en valor el ornamento, el trabajo manual de los artesanos locales, como afirma Rahmoun en el marco de la exposición de su obra Taqiya-Nor (2017) en la 57a Bienal de Venecia (Rahmoun citado por Art Jameel, 2018), más allá de ser un mero afán de reivindicar lo propio, es una "nueva economía de la racionalidad para impedir que la racionalidad moderna vaya más allá de los límites dados por la experiencia" (Foucault, 1988, p.4).

Se trata de buscar lo marginado y lo desprestigiado, una concepción del arte como ejercicio ritual que encuentra sus orígenes en las ideas expresadas a mediados del siglo VI a. C. por el pitagorismo. Este movimiento a través de la reflexión multidisciplinar y la dialéctica entre astrólogos, músicos, matemáticos y filósofos llegó a la conclusión de que la esencia de todas las cosas del mundo se halla en los números (Jámblico, 2003). Concepción del mundo, que se desarrolla también en la cultura islámica a través de la ornamentación geométrica. Esto nos pone de manifiesto que el misticismo, que caracteriza el trabajo de Rahmoun, más allá de estar encerrado en el islam como religión, tiene una relación intrínseca con una forma particular de entender la fe, ya sea en el islam, el cristianismo o el judaísmo, una forma ligada al Mediterráneo como espacio filosófico y de diálogo intercultural. (Karroum, 2005, p.119)

\section{El arte como proceso autorreferencial}

El trabajo de Rahmoun no es un bloque indivisible, sino el resumen de su trayectoria vital, inquietudes y reflexiones espirituales y políticas. Para ello, es preciso tomar distancia para poder ver el todo, conocer con profundidad la producción artística y ponerla en contexto. Esta premisa que planteamos como estrategia de trabajo, ha sido el resultado del contacto directo con el artista, a través entrevistas, visitas a su lugar de trabajo, revisión de obras in situ y lecturas de textos críticos. Todo esto nos ayuda a comprender que detrás del carácter minimalista y de carga simbólica, existe una investigación en curso que se desarrolla en etapas entrelazadas e indefinidas.

Estas etapas las dividimos en tres periodos: debate de legitimación, viaje terrenal y viaje 
espiritual.

\subsection{Debate de legitimación}

Entre 1997 y 2001 el trabajo de Rahmoun se inclinaba hacia la investigación formal y experimental de las relaciones subyacentes de los materiales, el espacio, el contexto y las referencias culturales. De esta etapa cabe destacar su proyecto de fin de estudio ${ }^{2}$ Hajibat (1998), en el que el artista desarrolla siete versiones de piezas instalativas producidas con yute, para adaptarlas a los espacios de una casa tradicional tetuaní, situada en el centro histórico de la ciudad (ver Fig.1).

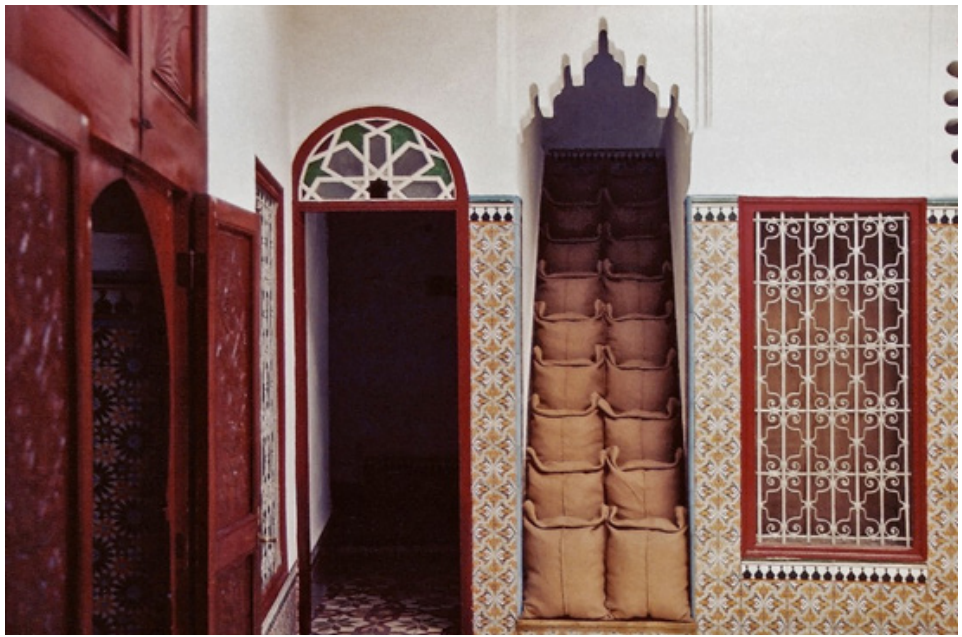

Figura 1. Younes Rahmoun, “Arpillera y aserrín M'wedna”, Hajibat, 1998. $240 \times 70 \mathrm{~cm}$. Copyright (C) Younes Rahmoun

Rahmoun en esta intervención, demuestra una prematura madurez en cuanto a la comprensión del arte contemporáneo. En vez de defender su trabajo en un marco institucional, dentro del Instituto Nacional de Bellas Artes (INBA), invita a los profesores que conforman el tribunal a trasladarse a la medina de Tetuán (entrevista con Rahmoun, 2019). Por tanto, se transforma así la esencia de la obra de arte en el gesto de andar como práctica artística, poniendo en tela de juicio la idea del arte como objeto, para insistir en el proceso que "conduce hasta los objetos" (Bourriaud, 2013, p.65).

Por otra parte, Rahmoun asume una de las características arquitectónicas ligadas a la cultura de su ciudad natal, que se fundamenta en el factor sorpresa. Lo bello en las sociedades islámicas tradicionales, y aquí excluimos las ciudades futuristas del Golfo Pérsico (Al-Maria, 2012), no se encuentra en el espacio exterior sino en la parte interior. Como explica Claude Hagège en Les Religions, la Parole et la Violence (2017), los espacios de habitar son al fin y al cabo frutos de la percepción espiritual de la vida. Un concepto que Rahmoun aplica en este proyecto, a través del uso de materiales pobres y el monocromo. Las formas resultantes por tanto, no son elementos ajenos al contexto, sino construcciones provenientes de las prácticas cotidianas, de los objetos 
de uso diario y de las tradiciones locales.

En línea con esta idea, cabe destacar que en los inicios de Rahmoun identificamos la existencia de influencias directas de sus profesores Faouzi Laatiris y Hassan Echair, especialmente en la disposición espacial de las obras y en la manera de concebir el arte a través de la idea del marco derridiano, donde el marco como entorno o lugar de exhibición, es el eje fundamental para expresar la verdad que pretende representar la obra. (Foster, et al., 2006, pp.44-46) No es lo mismo exhibir unos sacos de yute en el mercado de la medina de Tetuán, que hacerlo en una casa tradicional, como sucede en Hajibat. Se trata de una idea que ya encontramos defendida en los readymades de Marcel Duchamp y en las intervenciones de los artistas Fluxus de los años 50 y 60 del siglo $X X$, donde se pierde el aura de la obra de arte como genialidad mágica, para valorar el impacto del espacio expositivo sobre ella. (Montazami, 2017)

\subsection{Viaje terrenal}

La segunda etapa de Rahmoun tiene una relación intrínseca con su viaje a Europa en 1999, en el marco de la exposición l'Objet Désorienté au Maroc (El objeto desorientado en Marruecos), que se llevó a cabo en el Museo de Artes Decorativas de París (Beaud, et al., 1999). Después de este viaje, Rahmoun da un salto importante en su carrera artística, puesto que entra en contacto con el curador Abdellah Karroum, con quien mantendrá hasta hoy en día una estrecha colaboración. Así mismo con el artista Jean-Paul Thibeau, que traslada a Rahmoun su percepción del arte como proceso relacional de transformación permanente, alejado del contexto oficial del arte y abierto a posibilidades de experimentación y del conocimiento del Otro. Rahmoun aplica dicho proceso un año más tarde junto a Thibeau, en Expédition du bout du monde (2000), que consistió en una convivencia en una casa humilde de un pueblo de las montañas del Rif llamado Champs de l'Arabe. En este espacio alejado del centro, surgieron debates e intercambios con los habitantes, llevando a la práctica los propósitos de Karroum como precursor de este proyecto que pretendía según él: "desplazar el centro de interés hacia el territorio y el presente" (2015, p.11).

El viaje, en este caso, no es solo un traslado físico de un lugar a otro, sino también una posibilidad de conocer la diferencia. Se trata de salir de la mirada hipnótica y soñadora que contempla desde la miseria y detrás de las fronteras, intentando evadir sus sueños contenidos, construyendo paraísos fantaseados en la otra orilla del Mediterráneo, como sugiere Yto Barrada a través de su obra Wallpaper, Tangier (2001). En palabras de Rahmoun: “Cuando era niño, soñaba con ser un gran viajero, convertirme en marinero, para poder navegar en busca de un lugar perfecto, un lugar ideal, un paraíso, en algún lugar de la Tierra" (Rahmoun, 2009).

\subsection{Viaje espiritual}

Tras alcanzar dicho viaje terrenal, Rahmoun se libra del ansia de atravesar el "estrecho de sentido único", para comenzar a partir de 2001 a interesarse en el viaje espiritual.

"Ahora que he tenido la oportunidad de viajar por el mundo, estoy seguro de que, si existe en esta vida, el paraíso o ese lugar ideal, no se encuentra en el extranjero; existe en mi casa, en mi país, en mi ciudad, en mi vecindario, en mi pequeño cuarto "ghorfa", aquí mismo, en algún lugar dentro de mi propio corazón. Es cierto que la palabra "viajar" es parte de mi vocabulario. La imagen del barco que aparece en algunas de mis 
instalaciones, como "Markib" (2005), o la semilla que viaja por el espacio en mi video "Habba" (2008) para mí representan la noción de viaje" (Rahmoun, 2009).

Esto no significa una ruptura estética en el trabajo de Rahmoun con lo anterior, sino una continuidad y evolución alineada con los cambios que va experimentando como artista y como persona. En otras palabras, empieza a estar atento a lo que ocurre a su alrededor y a comprender la vida como etapa transitoria y efímera como señala en 2004 a través de su obra Layssa Lilkafani jouyoub (una mortaja no tiene bolsillos), construida a partir de una peana de madera apoyada en la pared y una tela blanca doblada y colocada encima (ver Fig.2).

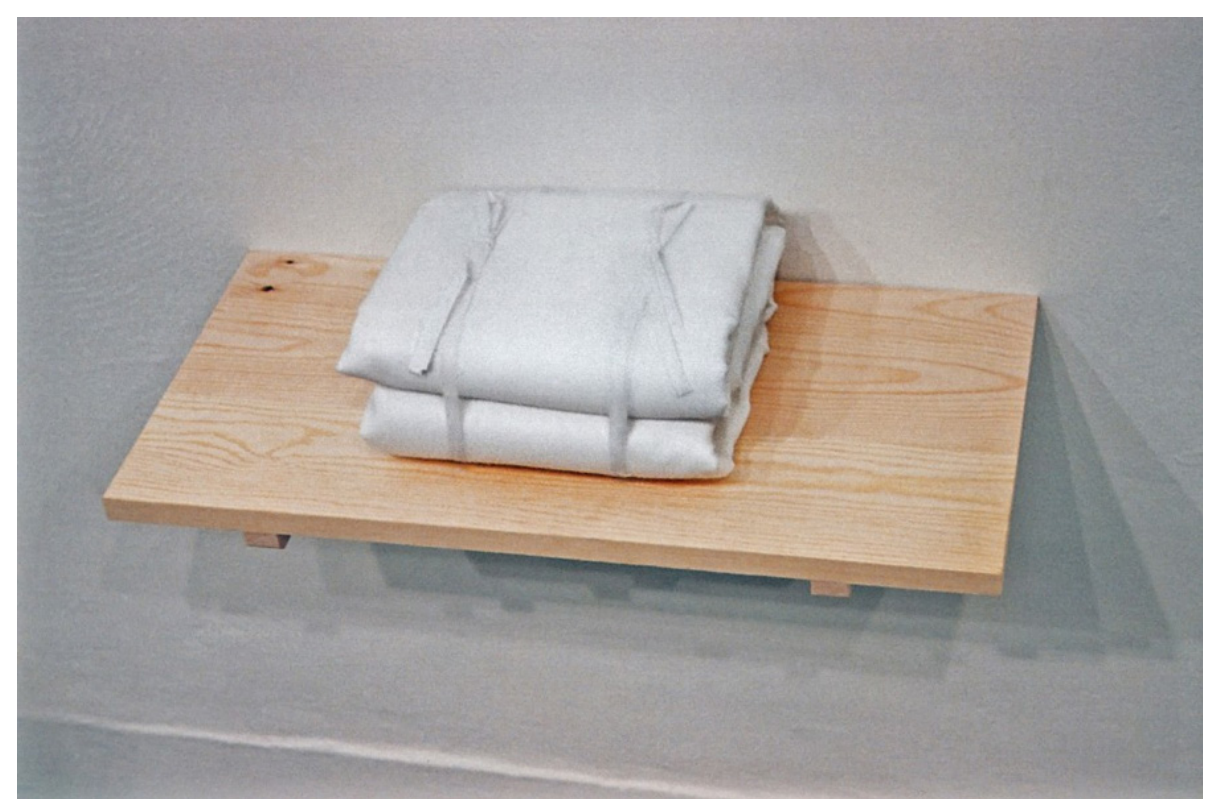

Figura 2. Younes Rahmoun, Layssa Lilkafani Joyous, 2004. Tela y madera. $21 \times 20$ x $9 \mathrm{~cm}$ (tela). $50 \times 25 \times 0.17 \mathrm{~cm}$. Madera. Copyright (C) Younes Rahmoun

Esta conciencia del yo, lleva a Rahmoun a indagar en sus creencias y a incorporar diferentes elementos simbólicos como el número 99, la orientación hacia la Meca, la luz y el color verde. Una de las estrategias de emprender ese viaje espiritual que recuerda a los maestros derviches, que dan vueltas y vueltas durante largos espacios temporales, para aproximarse a lo divino se manifiesta en la obra performativa Wahid, (2001) que se presenta en formato vídeo desde 2003. En ella el artista desarrolla una acción en la que aparecen solo sus manos emergiendo de la djellaba negra que lleva, con la capucha cubriendo su cabeza y su cara; sentado con las piernas cruzadas en un cuadrado de tela negra colocada en el suelo y mirando a La Meca, mientras repite la palabra "wahid" 99 veces en 99 segundos en un tono de voz medio. Solo sus dedos se mueven, marcando las 99 palabras, una por segundo (ver Fig.3).

Repetir la palabra wahid (uno) es una afirmación y una búsqueda de esa abstracción no representativa que observamos en el arte y la arquitectura islámica, donde lo divino está en todas partes, en la respiración, en la voz, en nuestro cuerpo, en el aire que respiramos, en la luz, 
en el agua, en la materia, en el universo, etc.

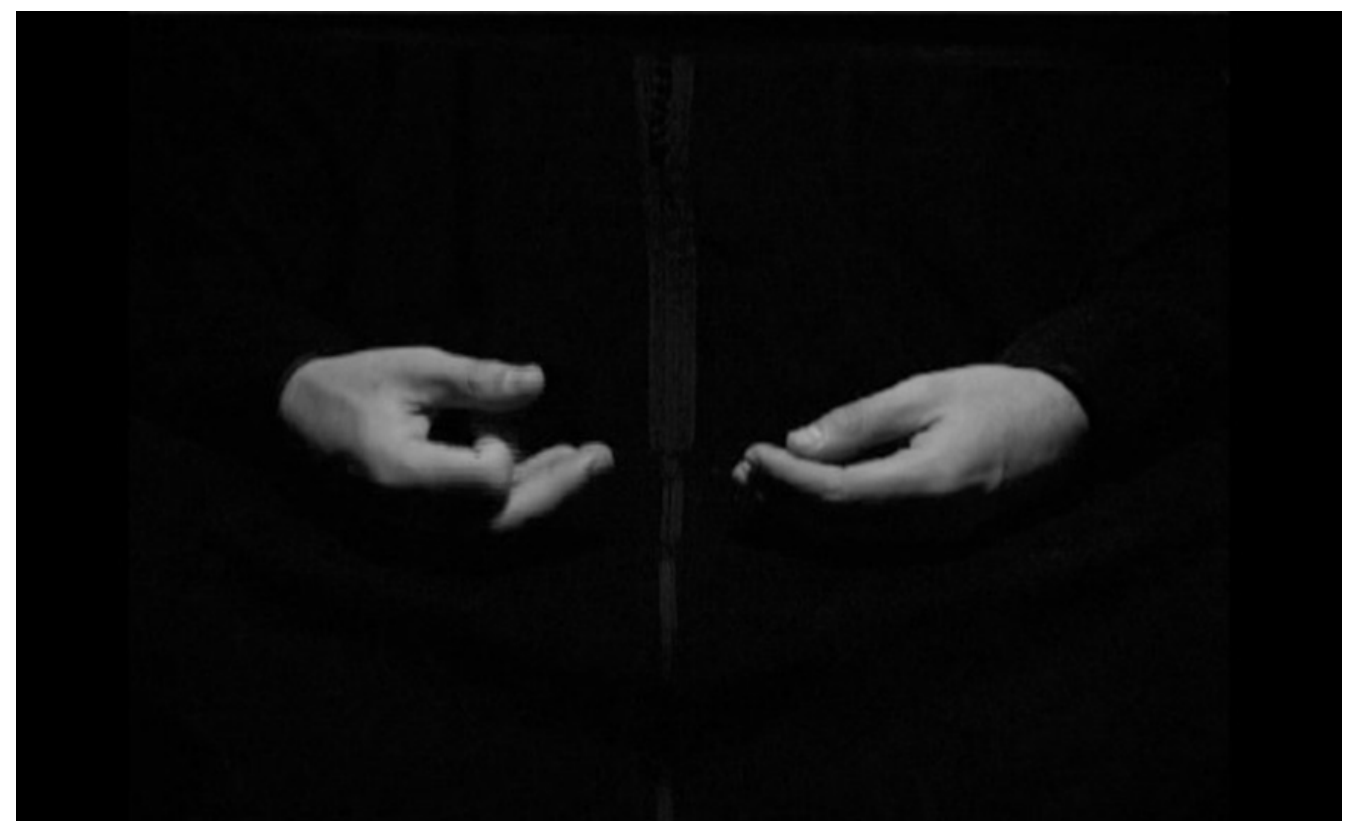

Figura 3. Younes Rahmoun. Wahid, 2003. Cinta de video en blanco y negro, $99 \mathrm{s.}$ Copyright (C) Younes Rahmoun

Por tanto, el viaje de Rahmoun no es sólo individual, sino compartido con el espectador a través del empleo de la estética minimalista y la incorporación de elementos simbólicos que hacen alusión a sus creencias. Pero no con ello estamos ante la defensa de una doctrina, más bien tal y como explica el artista en una conversación con Karroum, a partir de su fe, trata de generar conexiones con el Otro. Aquí cabe citar su intervención en La Fôret d’Art Contemporain (2014) donde en el marco de sus intervenciones en siete puntos específicos, coloca en la fachada de la iglesia Saint Michel siete bombillas, creando la forma de una casa a la que titula Manzil-Misbah (casa lámpara) para hablar del más allá, donde según él reside Dios y Su Reino (Al-Malakut) (ver Fig.4).

La relación existente entre la espiritualidad y el arte que reparamos en la obra de Rahmoun, no es sinónimo de un distanciamiento de lo real o de los problemas existentes, sino más bien, es una toma de distancia autoimpuesta que proporciona "conocimiento". Argumentando esta idea nos apoyamos en una declaración del artista en la que dice:

"Para mí, la religión no está separada de otros dominios de la vida. Es política, económica, social, etc. En cualquier caso, así es como entiendo la religión. No distingo "Younes, el musulmán practicante" y "Younes, el artista". Soy ambos. Lo que hago es simplemente un reflejo de mí mismo. En mi trabajo artístico, trato de descubrirme y explicar mi propio camino de exploración" (Rahmoun, 2009). 


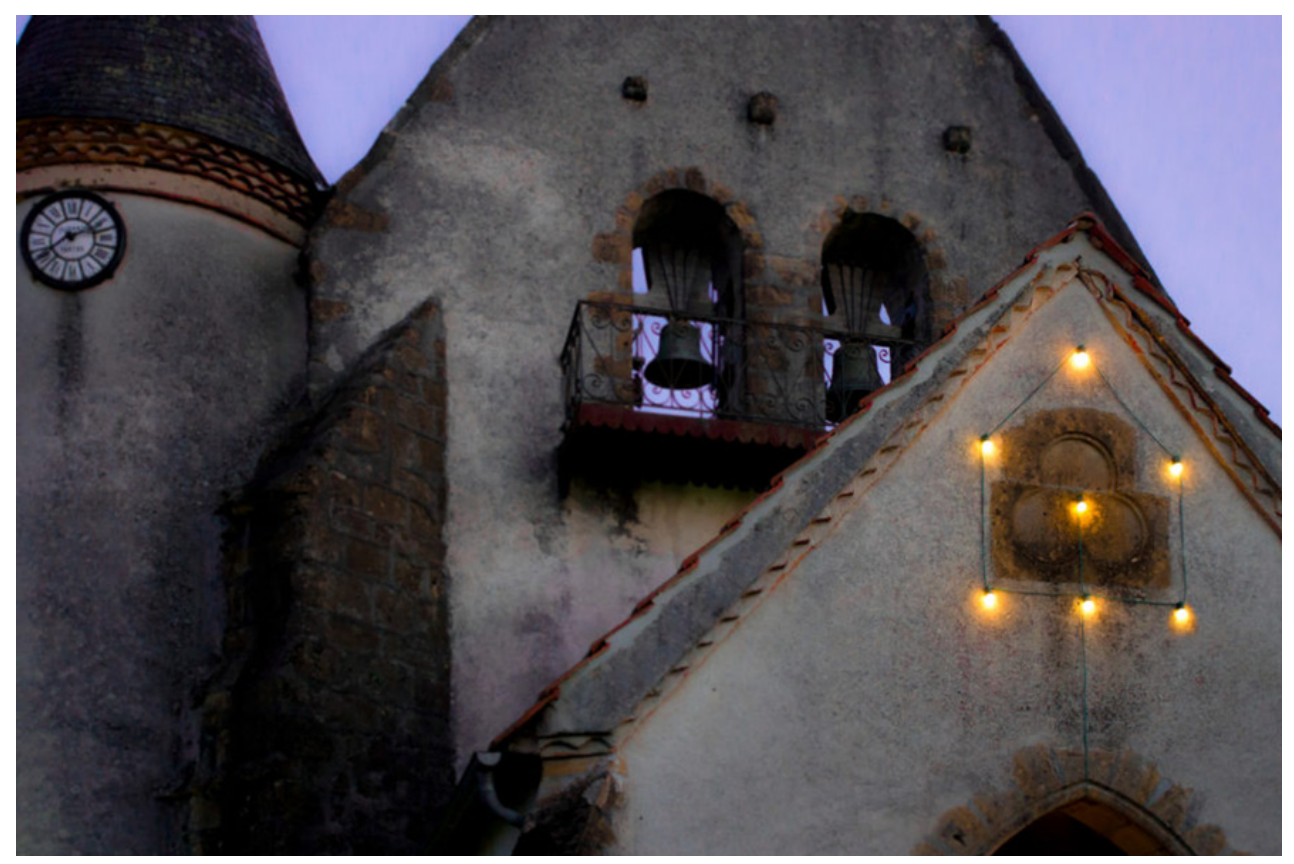

Figura 4. Younes Rahmoun. Manzil-Misbah, 2014. Bulbs, clavos, cables y electricidad. 120 × 150 x $12 \mathrm{~cm}$. Copyright (c) Younes Rahmoun

Teniendo en consideración esta declaración, entendemos que bajo la percepción inofensiva de la obra de Rahmoun existe un compromiso ético-político, particularmente cuando reflexiona sobre cuestiones ligadas al territorio del Rif o sobre el viaje, que por un lado puede remitir a la Hijra (emigración) de Mahoma y por otro a la necesidad de un desplazamiento por causa del contexto político o por las desigualdades existentes. El trabajo de Rahmoun más allá de buscar recriminaciones amargas y desesperadas o un afán de venganza, combina armoniosamente el binomio poiesis y mímesis. Rahmoun, por medio de la ficción, propone ofrecer al espectador la suficiente autonomía en relación con los modos con los cuales se articulan los significantes, alterando el sentido común de la interpretación de lo real, una labor que cada vez resulta más difícil de alcanzar puesto que vivimos inmersos en un mundo sin rumbo (Lipovetsky, 2013) y saturado de imágenes (Sontag, 2018).

\subsection{La obra de arte como proceso relacional}

(...) "comencé a pensar que trabajar con el número 99 es un poco pretencioso por mi parte como ser humano. Me preguntaba ¿Cómo puedo utilizar un número que representa los nombres que existen de dios en el islam?" (Y. Rahmoun, comunicación personal, 3 de abril de 2019).

Como respuesta a esta pregunta, surge una de las obras más importantes de Rahmoun que lo lleva a abandonar el número 99 y sustituirlo por el número 77, no solo a nivel estético o de dimensiones, sino también por su complejidad. Se trata de Zahra (flor), que comenzó en 2008 
como una serie de dibujos de flores construidos a través de repeticiones sistemáticas del círculo, cuyo fin es forjar una reflexión de la representación similar a la que se halla en la ornamentación islámica, donde se limita la reproducción de lo real en pro del concepto (ver Fig.5).

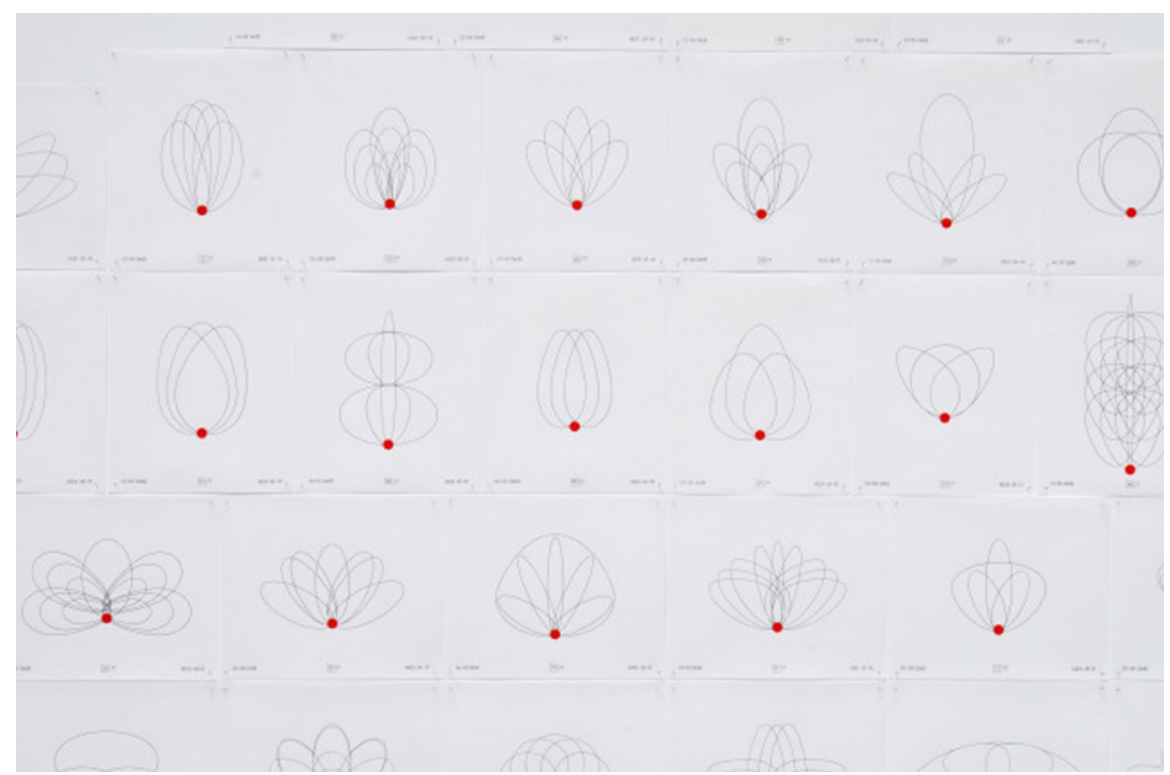

Figura 5. Younes Rahmoun. Zahra-Saghira, 2008. Pegatina y lápiz sobre papel, vidrio, cartón y clavos. $32,5 \times 25 \mathrm{~cm}$ cada pieza. Copyright (C) Younes Rahmoun

Según Rahmoun:

“(...) En 2008 había dibujado 77 flores diferentes, que en realidad no representan flores que existen en la naturaleza. Era la época en la que voy a pasar del monocromo, de trabajar con un solo color, a trabajar con todos los colores y a utilizar la luz en mi trabajo para representar la parte espiritual del ser humano" (Y. Rahmoun, comunicación personal, 3 de abril de 2019).

Zahra por consiguiente, es una de las líneas de trabajo más importantes en la trayectoria del artista, puesto que a partir de Zahra, Rahmoun abandona el monocromo para incorporar color, un hecho que lo llevó a materializar Zahra-Zoujaj (2010), contando con la colaboración del arquitecto español instalado en Ceuta Carlos Pérez Marín. Zahra-Zoujaj es una obra monumental caracterizada por su estructura externa octagonal donde se sitúa una estrecha puerta que obliga al espectador a inclinarse para poder acceder a su interior. Una vez dentro el espectador descubre un grupo de setenta y siete flores de vidrio soplado suspendidas en el techo, del revés. Las flores se hicieron durante la residencia del artista el Centro International d'Art Verrier de Meisenthal (CIAV), utilizando los setenta y siete dibujos realizados para la obra Zahra, que luego se adaptaron a las limitaciones del vidrio (Waymann, 2011, pp.28 - 29). Aunque cada flor es única, todos sus centros están hechos de una bola roja idéntica desde la cual se genera una suave luz roja y cuya intensidad aumenta o disminuye según los diferentes ritmos. Solo después 
de unos minutos de atención, la docena de espectadores que pueden entrar en este estrecho espacio al que Rahmoun llama "Hujra" (habitación), pueden distinguir los coloridos y los matices de cada flor instalada en una cúpula alrededor de siete círculos concéntricos (Rahmoun 2010). Rahmoun en esta obra desarrolla concretamente lo que Jacques Rancière describe como el reparto de lo sensible, donde la obra de arte "es a la vez el espacio de una actividad pública y el lugar de exhibición" (2014, p.23) (ver Fig. 6).

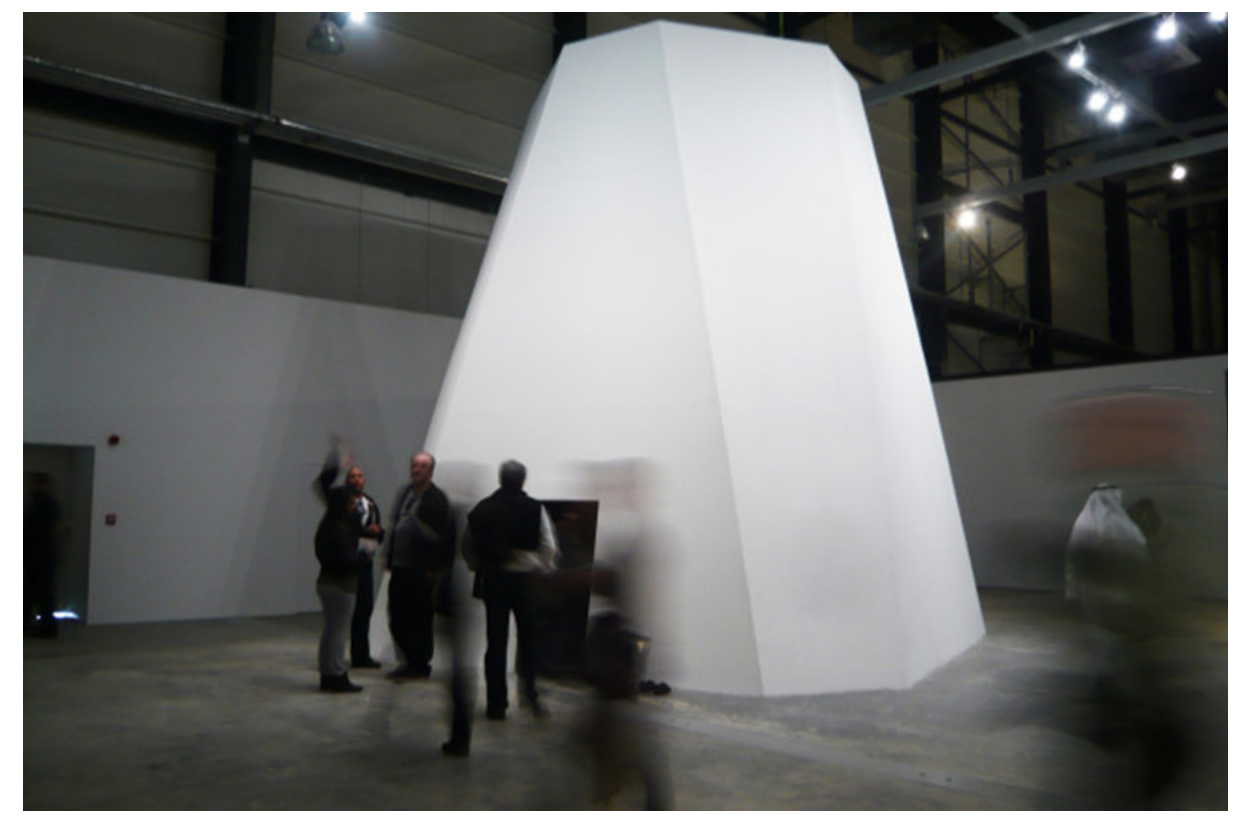

Figura 6. Younes Rahmoun. Zahra-Zoujaj, 2010. Vidrio, espejos, fieltro, LEDs, cables, madera, estructura metálica. 700 × 600 × $500 \mathrm{~cm}$, La flor: $50 \mathrm{~cm}$ de altura. Exposición colectiva Told / Untold / Retold (2010-2011) en Mathaf, Arab Museum of Modern Art Doha, Qatarj. Copyright (C) Younes Rahmoun

Los espectadores "habitantes" de ese espacio-obra, invitados por el artista a interactuar con su obra, son aquellos que son capaces de esperar y ralentizar sus ajetreadas vidas, es decir esos seres sensibles que señala Kandinsky "como los buenos violines muy usados, que con cada ligero contacto del arco vibran en todas sus partes y partículas" (1989, p.43). De este modo, lo que se busca no es el impacto de una primera percepción pasajera, sino los efectos perdurables que produce en el cuerpo. Para mantener viva la emoción, Rahmoun en Zahra-Zoujaj interactúa con el espectador, situándolo en un espacio reducido bajo decenas de lámparas en forma de flores de diferentes colores, donde se busca en primer lugar sorprender y por otro desplazar el Yo hacia el espectador como el propio artista afirma en una entrevista realizada por Sandrine Wyman, recitando una frase del Corán que dice: 'Dios es Bello y ama la belleza' (CIAV Meisenthal - France, 2014). La belleza que busca el artista va más allá de la superficialidad, es un concepto abstracto, inmaterial y austero. El espectador ante Zahra-Zoujaj, desde fuera solo es capaz de visualizar una estructura geométrica racional blanca de apariencia minimalista, pero al entrar a ese reducido espacio, descubre un mundo inmenso al que aparentemente hemos dado la espalda. Se trata de devolver el hombre al mundo, tocar esa parte sensible que se ha desvanecido con la razón moderna, de ahí el hecho de generar un cambio entre el espacio 
exterior e interior, obligando a los espectadores a entrar descalzos para volver a tocar tierra y a sentir su fragilidad como seres vivos (ver Fig. 7).

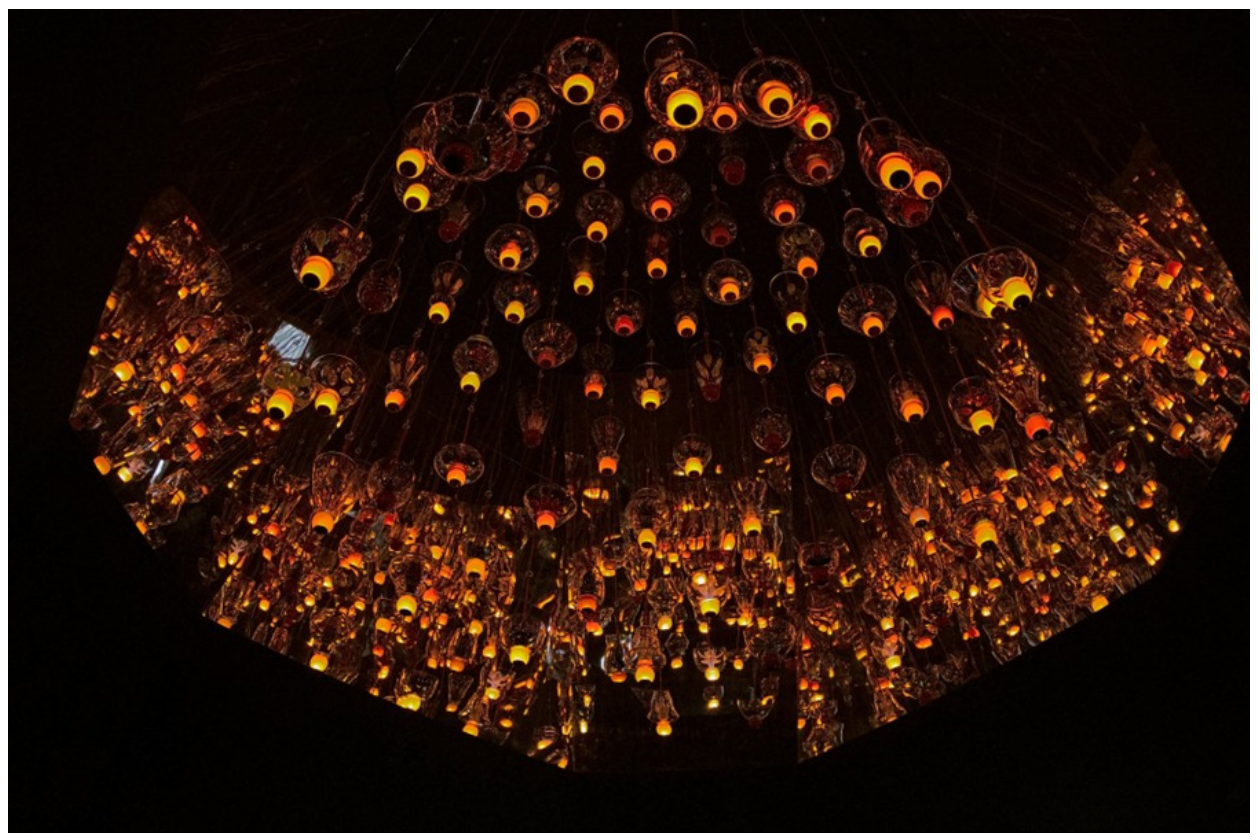

Figura 7. Younes Rahmoun. Zahra-Zoujaj, 2010. Vidrio, espejos, fieltro, LEDs, cables, madera, estructura metálica. 700 × 600 × $500 \mathrm{~cm}$, La flor: $50 \mathrm{~cm}$ de altura. Exposición colectiva Told / Untold / Retold (2010-2011) en Mathaf, Arab Museum of Modern Art Doha, Qatarj. Copyright (C) Younes Rahmoun

En este sentido, no hemos de obviar el proceso previo que llevó al artista a materializar ZahraZoujaj, el trabajo de Rahmoun se articula por medio de un ejercicio de repetición que recuerda a los pequeños movimientos de Wolfgang Laib filtrando el polen de avellana como acto de meditación para crear formas geométrico-cromáticas que transforman el espacio expositivo en santuario. A partir de este principio entendemos que existe, en la obra de nuestro artista objeto de estudio, una disolución de los límites entre el arte y la vida. Esta última idea se ve detallada por el investigador Luca Pantina en su tesis doctoral El arte como forma de meditación (2019), apoyándose en una entrevista del artista italiano Michelangelo Pistoletto en la que afirma que "el arte está justo al lado de la idea de la espiritualidad y de la capacidad humana para responder, a través de la creatividad" (Pistoletto, citado por Pantina, p.55). A tenor de las consideraciones de Pistoletto podemos decir que en el caso particular de Rahmoun, estamos ante una relación indivisible entre lo introspectivo que define François Cheng en su ensayo De l'âme (2016) como alma y la espiritualidad como experiencia que trasciende lo terrenal para buscar sentido a la vida. Para argumentar esta idea tenemos como ejemplo el uso que el artista hace de elementos simbólicos ligados a la experiencia autobiográfica como la luz, el color o la materia para hablar de lo divino. De ahí, podemos generar paralelismos entre la definición que plantea Cheng, diciendo que "el alma es el bajo continuo que resuena en cada uno de nosotros" (pp.42-43), con el funcionamiento técnico de Zahra-Zoujaj, donde aparecen en todas las flores unas bolas idénticas que palpitan una luz roja que brilla y desvanece cada determinado tiempo. 
Las bolas rojas de Zahra-Zoujaj, son una referencia simbólica al alma (roh en árabe) que es la esencia abstracta que diferencia a los individuos. Roh en la cultura islámica está unida al soplo de la vida, en otras palabras, a los pálpitos del corazón.

Frente a este universo creado por el artista para recordar la esencia de nuestra existencia y nuestra relación con el más allá (Al-malakut), el espectador podría mantener una postura distante, pero también está a su alcance el ir más allá del decorado, participar y formar parte de la obra. La finalidad por tanto de la obra de Rahmoun no es su aspecto decorativo, sino la experiencia emocional que transmite, cuyo efecto es permitir que el espectador sea capaz de llegar a lo que Roland Barthes (2007) llama "el clic", el momento en el que el público se fusiona con el Yo del artista.

\section{Coherencia discursiva}

Como hemos mencionado anteriormente, el trabajo de Rahmoun no se puede leer de manera fragmentada, sino como un discurso coherente que va evolucionando y adquiriendo nuevas formas, interpretaciones, materiales, etc. Esto explica la relación formal y estética que podemos encontrar entre Zahra-Zoujaj y el proyecto Ghorfa, especialmente en la percepción del espacio y la relación con el espectador. Ghorfa en su esencia, es un espacio que el artista a menudo reproduce a escala 1/1 para referirse a la pequeña habitación que su madre le ofreció en 1998 como espacio de trabajo y como modo de organización del lugar en una familia numerosa. Un espacio que se encontraba según el artista bajó las escaleras y en dirección a La Meca, allí era donde Rahmoun reflexionó, produjo y meditó durante 7 años. Este habitáculo al que Rahmoun llama Ghorfa era su único refugio, un lugar cuya historia según él está completamente conectada con su propia historia. (Rahmoun, 2009)

Ghorfa como obra no tiene un único formato o una estética determinada, va evolucionando según el contexto en el cual se desarrolla, desde un plano en forma de contorno en L'appartement 22 (2005-2006), en Rabat, a madera en la Bienal de Singapur de 2006 o a piedra y materiales locales en Beni-Boufrah, la aldea de la cual procede la familia del artista en las montañas del Rif marroquí. Esta última versión es extremadamente importante para el artista, ya que para él supone un pretexto para socializar e intercambiar conocimientos de manera horizontal donde la obra se encuentra en el espacio tiempo de experiencia y no en el objeto resultante. Es decir, se halla en el proceso de obtención de los materiales, en el diálogo con la gente sobre el significado de la obra, de la necesidad de explicar el porqué de la obra y su localización, así como, en las diferentes posibilidades de construcción y los materiales necesarios. Según el artista todo esto convierte sus intervenciones en piezas colectivas aptas para mudarse de un lugar a otro, puesto que se fundamenta sobre el principio de la comunicación (Rahmoun, 2009). (ver Fig. 8, 9, 10). 


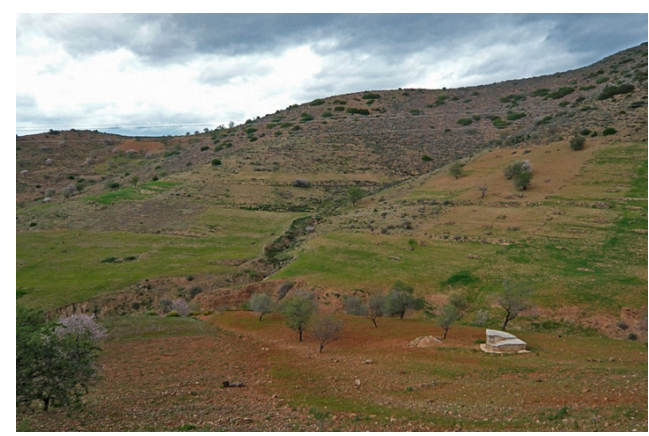

Figura 8. Younes Rahmoun, Ghorfa \#4, Al-Ana/Huna, 2007. Piedra, tierra, madera y hormigón. 214 x 236 x $185 \mathrm{~cm}$, Intervention Beni-Boufrah, Rif, Marruecos. Copyright (C) Younes Rahmoun

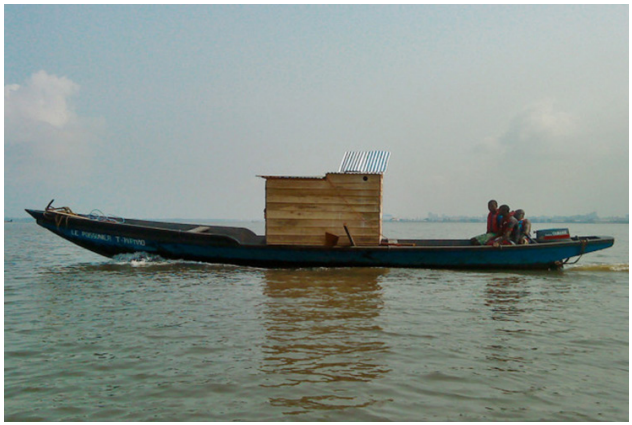

Figura 9. Younes Rahmoun, Ghorfa \#7, Al-Ana/Huna, 2010. Madera y chapa ondulada de zinc. 214 x 236 x $185 \mathrm{~cm}$. Intervención en el contexto de la exposición colectiva SUD2010. Trienal Douala, Camerún. Copyright (C) Younes Rahmoun

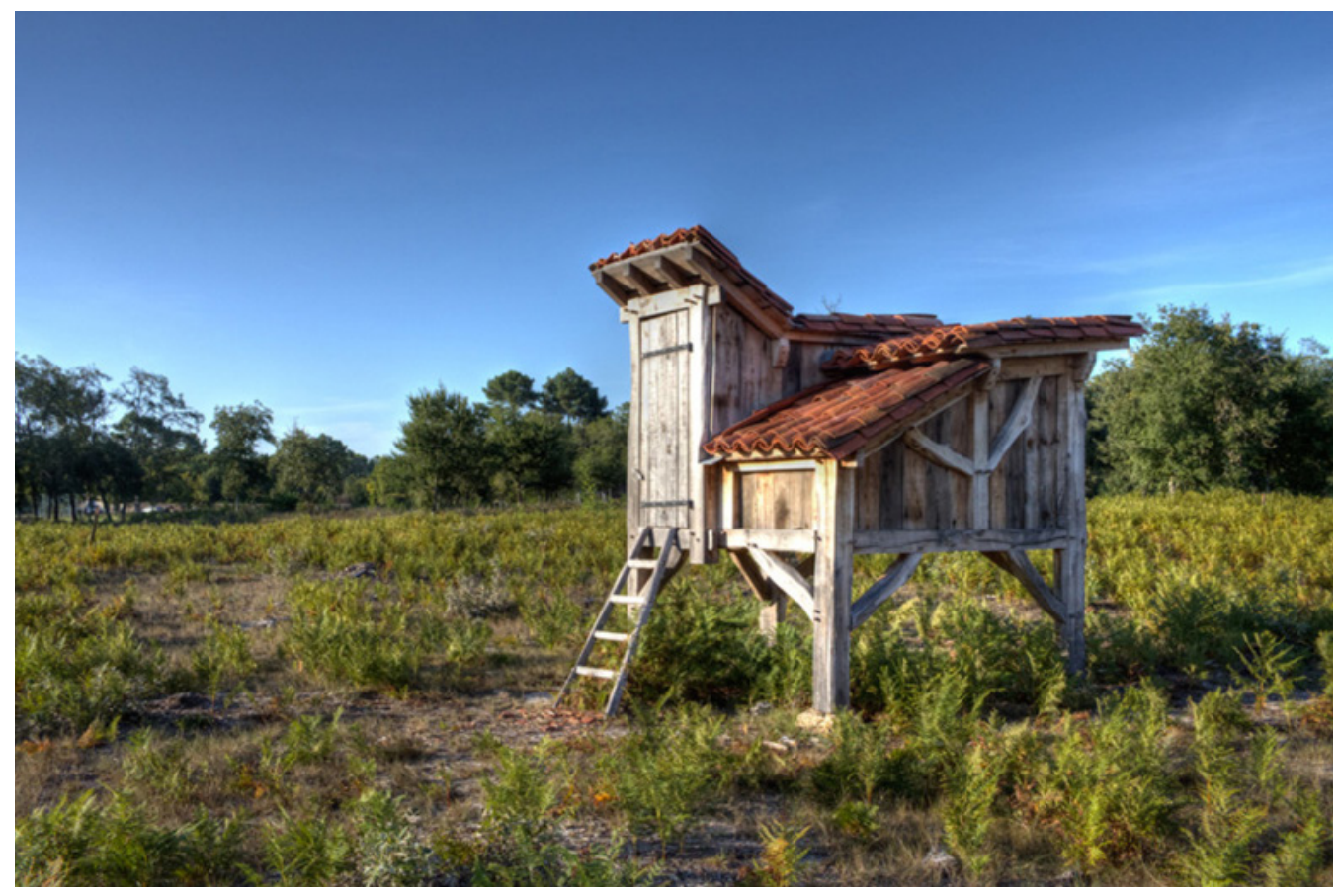

Figura 10. Younes Rahmoun, Ghorfa \#9, Al-Ana/Huna, 2014. Madera, tejas y piedras. $214 \times 236 \times 185$ $\mathrm{cm}$. Intervención en Vert Village, Landes, Francia. Copyright (C) Younes Rahmoun 


\subsection{El andar como práctica artística}

El carácter expositivo, por tanto, es solo la cara visible de la obra de Rahmoun, la esencia de su trabajo se fundamenta en el gesto de andar, en sus constantes viajes hacia el poblado de sus antepasados Beni-Boufrah. Rahmoun, en este viaje solitario al que titula Hijra / Rif, lleva a la práctica precisamente aquel tiempo lúdico de experimentación dedicado al nomadismo que cita Francisco Careri (2004, pp.29-38), a través de la recogida de siete piedras desde un punto concreto, para situarlas en otros lugares del mundo y reemplazarlas por otras piedras recolectadas durante sus múltiples viajes (ver Fig. 11).
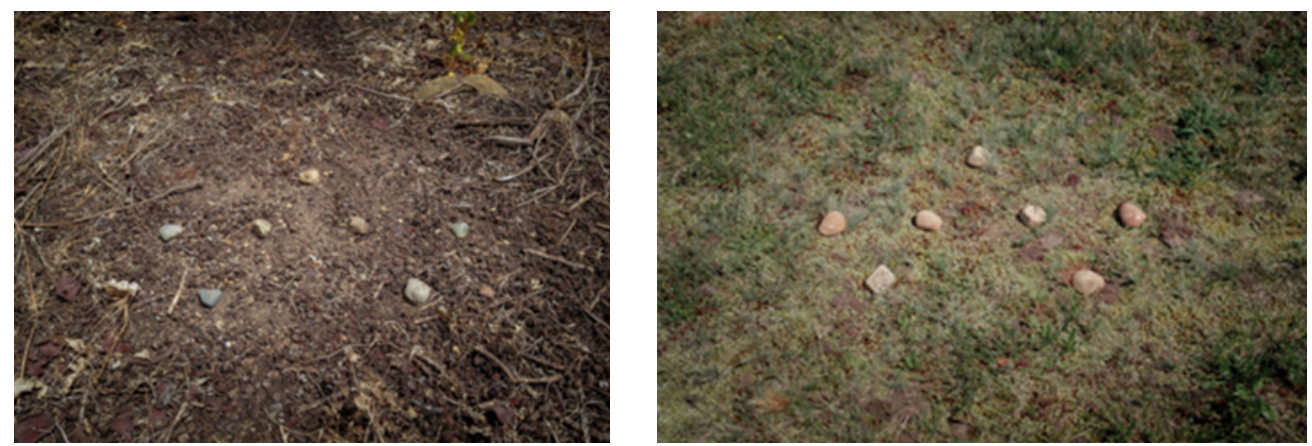

Figura 11. Younes Rahmoun, Hijra / Rif-Landas, 2014. Dimensiones variables. Intervención en Beni-Boufrah, Rif, Marruecosy y en Vert Village, Landes, Francia. Copyright @ Younes Rahmoun

Rahmoun de esta manera, por un lado, indaga en sus orígenes y en su relación personal con la experiencia de emigrar y por otro, explora la conexión entre los materiales orgánicos naturales de la tierra y su papel en la construcción de la identidad colectiva y la pertenencia. En efecto, se podría decir que existe una frágil figura del hogar como sinónimo de la nostalgia y el aferramiento a los orígenes de sus antepasados. El aferramiento aquí se articula por medio de una estética de doble función: por un lado, se construye figurativamente una estructura material alrededor de situaciones no resueltas; y por otro, se transforma el hogar en un sitio potencial para compromisos empáticos con el sufrimiento de los demás. De ahí podemos entender la práctica del andar como acción artística, donde las pequeñas intervenciones que comienzan en Rif terminan adaptándose a otros lugares como Senegal, Francia, Estados Unidos, Líbano, Jordania, Inglaterra o Qatar.

Mediante gestos sencillos de recoger y tirar, Rahmoun genera dibujos y formas que lo llevan a desarrollar obras escultóricas y expositivas como Markaba (2016), que nace de las líneas imaginativas resultantes de la disposición de las piedras en el espacio para pasar más tarde a ser materializada en los talleres de Fez. Markaba, como su nombre indica, evoca inmediatamente a un desplazamiento. Se trata de una obra compuesta por seis pirámides de cobre que muestran una silueta geométrica singular, la cual suscita un espacio para la meditación individual, donde la geometría manifiesta una nueva manera de concebir los materiales y las formas para crear mecanismos meditativos que posibilitan ver e imaginar las constelaciones de pequeños mundos y estructuras complejas en la vida diaria y en el universo (ver Fig. 12). 
Otra de las metodologías de trabajo de Rahmoun, es la concepción de su obra como objeto en movimiento. Markaba o Ghorfa son dos ejemplos de obras que forman parte del viaje físico y espiritual que experimenta Rahmoun, ya sea mediante el traslado de elementos de un lugar a otro o en la construcción de diferentes versiones de las mismas con el fin de convivir con otros espacios y que el contexto tome parte de sus significados. Para cumplir dicho objetivo, Rahmoun en sus intervenciones a menudo no suele utilizar materiales sólidos que alteren el espacio, más bien se limita a intervenciones despreocupadas por lo físico y objetual.

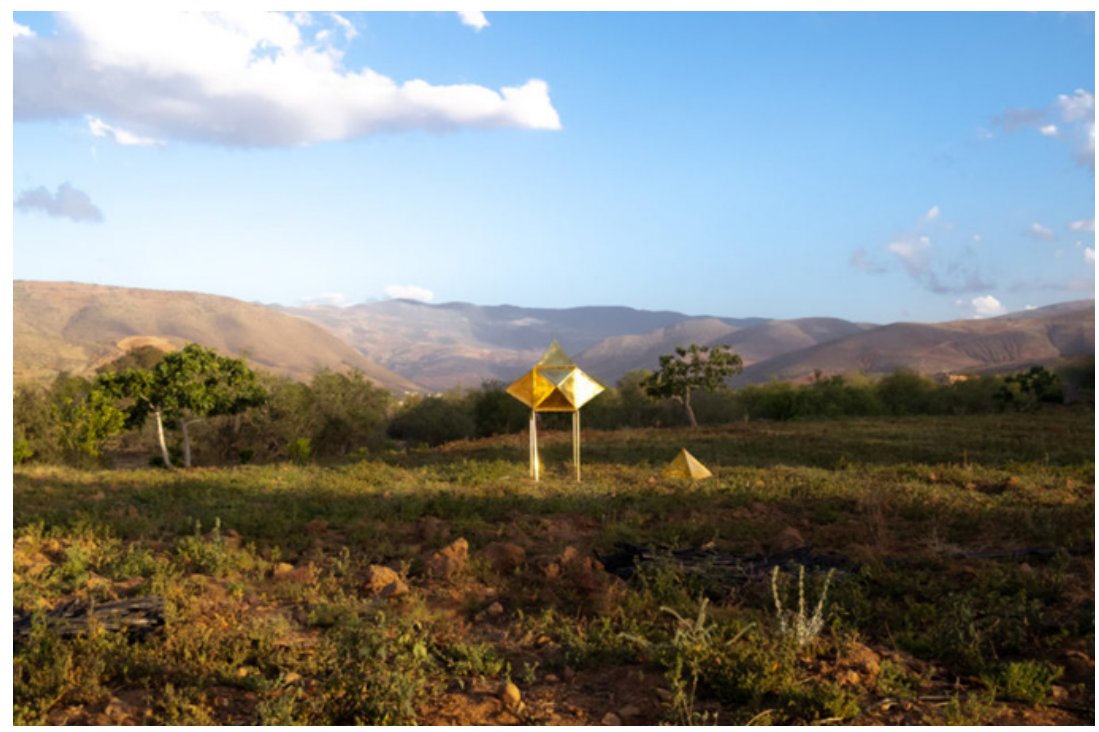

Figura 12. Younes Rahmoun, Markaba, 2016. Cobre. 170 x 170 x 240 cm. Intervención en Beni-Boufrah, Rif, Marruecos y exposición individual Younes Rahmoun: de la Mer à l'Océan en en L'appartement 22, Rabat, Marruecos. Copyright (c) Younes Rahmoun

\section{CONCLUSIONES}

Respondiendo a la hipótesis planteada en este estudio, llegamos a la conclusión de que, efectivamente, la espiritualidad en la obra de Rahmoun es un modo con el cual el artista toma distancia de la realidad, para comprender la esencia de la vida. En otras palabras, las estrategias narrativas de Rahmoun nos hablan del silencio como instrumento de intervención e interacción con el espectador. Esta estrategia despegada de la contestación surge en un contexto en el cual existe una cierta inclusión de la otredad en los circuitos artísticos. Esta inclusión que caracteriza nuestra realidad postmoderna, según el artista finlandés iraquí Adel Abidin a través de su obra I'M SORRY (2008), aún sigue funcionando por medio del continuum historicista. Abidin refleja esta idea a través de una interpretación poética de la experiencia que tuvo en su primera visita a Estados Unidos. Cada vez que mencionaba que era iraquí la gente respondía "I'm Sorry", sorprendida. Esa demostración de sorpresa, como hemos explicado en el primer apartado, se encuentra en consonancia con las problemáticas de representación histórica. Durante mucho tiempo el árabe ha sido representado como irracional, violento, tribal, perverso, exótico y 
carente de cultura. Por tanto, a pesar de la inclusión existente en la actualidad, aún resulta difícil asimilar la existencia de un arte contemporáneo árabe más allá de las etiquetas identitarias. En este sentido, hemos tomado como principio a seguir el análisis del trabajo de Rahmoun desde la especificidad de su trayectoria artística, alterando así la retórica habitual.

Esto nos exige tener en cuenta lo que Didi-Huberman define en su ensayo Fasmas (2015) como "la mirada soñadora", refiriéndose a mirar aquello que se esconde tras el decorado. Nos referimos aquí al hecho de prestar atención a los aspectos simbólicos que caracterizan la obra de Rahmoun, como el uso de números impares para referirse a lo divino, el lugar comprendido como espacio de meditación, la idea del camino como proceso de conocimiento espiritual que lleva a los orígenes, como explica el artista diciendo: "quiero hablar sobre mis orígenes pero también sobre un movimiento en mi historia" (Rahmoun, 2018) o la austeridad en cuanto a los materiales utilizados y la importancia del significado de los mismos. El trabajo de Rahmoun, como hemos podido visualizar en las diferentes obras citadas en este estudio, no considera las expresiones artísticas tradicionales como una parte aislada de la creación, todo lo contrario; para él, las artes aplicadas representan sabidurías. De esta manera Rahmoun contradice lo que se ha venido defendiendo a partir de la percepción de Loos sobre el ornamento, proponiendo reeducar nuestra mirada como espectadores. No obstante, el ornamento en la obra de Rahmoun no es un continuismo o apropiación de procedimiento, sino un intento de compresión adaptado a los lenguajes representativos del arte contemporáneo.

A tenor de lo anterior, podemos decir que la obra de nuestro artista objeto de estudio no funciona por sí sola o de manera aislada del espectador. De hecho, no existe una división clara entre espiritualidad, autorreferencia y espectador. Rahmoun a partir de sus convicciones espirituales, busca la esencia de su realidad a través de la fijación en la materia y/o la representación minimalista. En este sentido, la formalización estética de su obra está ligada al contexto artístico local, muy influenciado por los debates de legitimación postcoloniales formulados por Fanon, de volver a la esencia de la cultura del sur global, a esa parte inmaterial y despreocupada por lo físico para comprender el significado y el valor original de lo cotidiano. 
Art Jameel. (Productor).(2018). Meet Younes Rahmoun, shortlisted for the Jameel Prize 5, for his work Tâqiya Nôr. [Video publicado en Facebook]. De https://www.facebook.com/ watch/?v=1978826325526166

Barthes, R. (2007). El placer del texto y la lección inaugural. Madrid: Siglo I.

Barroso, Villar. (2014). Arte Contemporáneo en el Norte de África. Oviedo: Julia Barroso Villar.

Benjamin, W. (2008). Tesis sobre la filosofía de la historia. México: Itaca.

Belmenouar, S. (2012). Art contemporain arabe. Transcontinentales. 13(12), 9. Recuperado de https://journals. openedition.org/transcontinentales/1317

Beaud, M-C., Froment, J-L. y Augé, M. (1999). L'objet désorienté au Maroc. Paris: Musée des arts décoratifs-Union centrale des arts décoratifs.

Bourriaud, N. (2013). Estética relacional. Buenos Aires: Adriana Hidalgo.

Careri, F. (2002). Walkscapes. Barcelona: Editorial Gustavo Gili, GG.

Cheng, F, (2016). De l'âme. Paris: Albin Michel.

CIAV - Meisenthal - France. (Productor). (2010). Les 77 lampes de Younes Rahmoun. [Video publicado en Vimeo]. De https:// vimeo.com/93640657

Derrida, J. (2006). Márgenes de la filosofía. Madrid: Cátedra.

Didi-Huberman, G. (2015). Fasmas. Cantabria: Shangrila.

Foucault, M. (1988). El sujeto y el poder Revista Mexicana de Sociología. Revista Mexicana de Sociología. 50(3), 3-20. Recuperado de https://terceridad.net/wordpress/wp-content/ uploads/2011/10/Foucault-M.-El-sujeto-y-el-poder.pdf

Favaretto, M.S. (2020). Las Fronteras de los archivos. Lo exótico en Pasolini. Arte Y Políticas de Identidad, 21, 52-73. Recuperado 
de https://revistas.um.es/reapi/article/view/416721

Fanon, F. (2017). Fundamentos recíprocos de la cultura nacional y las luchas de liberación. Los condenados de la tierra. (pp.161193). Tafalla (Navarra): Txalaparata.

Fatmi, M. (2011). Entrevista con Véronique Rieffel. Recuperado de http://www.mounirfatmi.com/critics-134.html

Foster, H., Buchloh, B., Krauss, R.y Bois, Y-A. (2006). Arte desde 1900 Modernidad, antimodernidad, posmodernidad. Madrid: Akal.

Hagège, C. (2017). Les Religions, la Parole et la Violence. Paris: OJ.SC.Humaines.

Kant, I. (2003). Lo bello y lo sublime. Madrid: Espasa Calpe.

Kandinsky, V. (1989). De lo espiritual en el arte. México DF., México: Editorial Premia.

Karroum, A. (2015). Sous nos yeux (Ante nuestros ojos). Sous nos yeux. Barcelona: MACBA; La Kunsthalle Mulhouse.

Lipovetsky, G. (2013). La felicidad paradójica. Barcelona: Anagrama.

Loos, A. (1908). Ornamento y delito. Paperback. Recuperado de http://www.infolio.es/paperback/articulos/loos/ornato.pdf

Malraux, A. (2013). There is no hierarchy in Art, 2013.

Recuperado de http://kaderattia.de/there-is-no-hierarchy-in-artandre-malraux/

Montazmi, M. (2017). Faouzi Laatiris: fugues chimériques dans la mondialisation. Revus desd mondes musulmans et de la Méditerranée, 141. Recuperado de https://journals.openedition. org/remmm/10162

Nava Murcia, R. (2012). El mal de archivo en la escritura de la historia. Historia y grafía - Deconstruyendo el Archivo.

38(19). México, Departamento de Historia de la Universidad Iberoamericana, 95-126. Recuperado de http://www.scielo.org. $\mathrm{mx} / \mathrm{pdf} / \mathrm{hg} / \mathrm{n} 38 / \mathrm{n} 38 \mathrm{a} 4 . \mathrm{pdf}$

Pantina, L. (2019). El arte como forma de meditación (tesis de pregrado). Universidad de Sevilla, Sevilla, España. 
Panzani, I. (2013). Walid Raad, "Scratching on Things I Could Disavow: A History of Art in the Arab World". Démocratiser l'art [contemporain]. Marges. 15, 166-167.

Ranciere, J. (2014). El reparto de lo sensible. Buenos Aires: Prometeo libros.

Rahmoun, Y. (2018). Younés Rahmoun: Little Worlds, Complex Structures. Qatar: Virginia Commonwealth University School of the Arts in Qatar.

Rahmoun, Y. (2009, 4 de Septiembre). Interior Travel. Entrevista con Jérôme Sans. Recuperado de https://www.younesrahmoun. com/interviews/interior-travel/

Read, H. (1975). Imagen e idea. México DF, México: Fondo de cultura económica.

Said, E. (2019). Poder política y cultura. Barcelona: Debate.

Said, E. (2013). Representar al colonizado: los interlocutores de la antropología. Reflexiones sobre el exilio (pp.179-218). Barcelona: Debolsillo.

Said, E. (2013). Orientalismo. [Versión E-Reader].

De https://www.tagusbooks.com/leer

Scheiwiller, S.G. (2018). (Neo)Orientalism: Alive and Well in American Academia: A Case Study of Contemporary Iranian Art. En T. Keskin. (Ed.), Neo-Orientalism, American Hegemony and Academia (pp.195-230). Boston: Turgut Keski.

Shabout, N. (2009). Newision Arab Contemporary Art in the 21st Century. Londres: Transglobal Publishing.

Sontag, S. (2018). Sobre la fotografía. Barcelona: Debolsillo.

Wymann, S. (2011, 4 de junio). Tetuán, Meisenthal, Doha. Novo, 12. Recuperado de https://issuu.com/media.pop/docs/novo_12 


\section{NOTAS}

1. Kalashnikov es un modelo de fusil fabricado por primera vez en 1947 por la Unión Soviética y convertido a partir de 2007 en el arma de fuego más producida del mundo, llegando a manufacturar cerca de 80 millones de unidades.

2. Para la obtención del título universitario de Licenciatura en el Instituto Nacional de Bellas Artes (INBA), el estudiante debe desarrollar un proyecto artístico argumentado teóricamente y una defensa del mismo. 